\title{
Lifestyle habits and womens attitudes towards discussing them at a visit for contraceptive advice
}

Ing-Marie Claesson, Eva Hultgren and Marie Blomberg

\author{
Linköping University Post Print
}

\section{Tweet}

N.B.: When citing this work, cite the original article.

Original Publication:

Ing-Marie Claesson, Eva Hultgren and Marie Blomberg, Lifestyle habits and womens attitudes towards discussing them at a visit for contraceptive advice, 2015, Sexual \& Reproductive HealthCare, (6), 3, 114-118.

http://dx.doi.org/10.1016/j.srhc.2014.08.002

Copyright: Elsevier

http://www.elsevier.com/

Postprint available at: Linköping University Electronic Press

http://urn.kb.se/resolve?urn=urn:nbn:se:liu:diva-122106 


\section{Lifestyle habits and women's attitudes towards discussing them at a visit for contraceptive advice}

Ing-Marie Claesson, Eva Hultgren, Marie Blomberg.

Division of Obstetrics and Gynecology, Department of Clinical and Experimental Medicine,

Faculty of Health Sciences, Linköping University, Department of Obstetrics and Gynecology in Linköping, County Council of Östergötland, Linköping, Sweden

Short title: Discussing lifestyle habits at contraceptive counselling

Keywords: Contraception, counselling, alcohol drinking, life style, tobacco, body weight.

\section{Correspondence:}

Ing-Marie Claesson

Division of Obstetrics and Gynecology

Department of Clinical and Experimental Medicine

Faculty of Health Sciences

Linköping University

SE - 58183 Linköping, Sweden

Tel. +46101032923

Fax: +4613148156

\section{Email: Ing-Marie.Claesson@liu.se}




\section{Abstract}

Objective: The aims of this study was to use visits for contraceptive counselling as opportunities for examining women's actual life style habits with the main focus being placed on alcohol consumption but also to evaluate the women's opinions about discussing their alcohol and tobacco habits and their weight status.

Methods: A total of 535/802 (67\%) women completed a study-specific anonymous questionnaire after a contraceptive counselling visit with a midwife.

Results: A majority of the women thought that a discussion concerning alcohol habits at a contraceptive counselling session was important (85.5\%) and not intrusive (86.4\%) neither embarrassing $(81.7 \%)$. Women with high-risk drinking habits were younger, more often tobacco users and more often planning for childbirth in the future, compared with women who did not display high-risk drinking behaviour. A significantly higher percentage of women who practiced high-risk drinking thought that a discussion of alcohol was intrusive $(10.9 \%)$ and embarrassing (46.7 \%), compared with women not practicing high-risk alcohol consumption. Most women (72.9\%) stated that no other caregiver during the preceding year except the midwife had discussed drinking habits with them. The weight was a good thing that the midwife brought up for discussion according to $82.5 \%$ of the women but the discussions about weight was more often found embarrassing (18.4\%) than the discussion about alcohol habits.

Conclusion: Women who came for contraceptive counselling found the discussion concerning alcohol habits important, not intrusive or embarrassing and a good thing to be brought up by the midwife.

Keywords: Contraception, Counselling, Alcohol drinking, Life style, Tobacco, Body weight. 


\section{Introduction}

Most women who come for contraceptive counselling are of childbearing age and are, in general, quite healthy with few other health care contacts. However, a recent national survey (2013) concerning lifestyle factors found that $6 \%$ of Swedish women aged 16-29 were obese, with Body Mass Index (BMI) $\geq 30$; comparable figures for women aged 30-44 were 11\% [1]. Another part of the survey reported that $24 \%$ of women aged 16-29 displayed a high-risk use of alcohol whereas only $9 \%$ of women aged 30-44 displayed this practice [2]. Hazardous drinking was defined as a consumption of more than nine standard glasses (12 $\mathrm{g}$ pure alcohol) per week or binge drinking more than three standard drinks on a single occasion [3]. Yet another section of the survey reported that $12 \%$ of a younger cohort were daily smokers in comparison with the older group of women where $7 \%$ were daily smokers [4]. An unhealthy life style poses a high risk for complications later in life [5-8]. The adverse outcomes of obesity, alcohol and tobacco consumption before and during pregnancy are well established [9-14].

There are a few Swedish studies that have investigated the extent to which patients in primary care have been questioned and have received advice about their health behaviours [15-17]. Studies reported varying degree of discussions around lifestyle habits. If lifestyle habits were discussed, the alcohol issue was touched to a lesser extent than issues concerning exercise, diet and tobacco.

Several studies have had the goal of investigating alcohol habits, consumption before and during pregnancy and perceptions of antenatal advice among women of childbearing age [1821], whereas among women in fertile age in contraceptive counselling, there are few studies, if any, which have investigated alcohol habits and opinions about discussing life style factors at these visits. It appears to us that staff at the contraceptive counselling units might have an 
excellent opportunity to discuss life style aspects and to inform women about the importance of general alcohol abstinence when planning pregnancy. We do not yet have any knowledge about how the women relate to such information if provided during counselling.

The primary aim of this study was to examine women's actual life style habits with the main focus being placed on alcohol consumption. The secondary aim was to evaluate women's opinions about being engaged in discussions about their alcohol and tobacco habits as well as their weight status, discussions that might take place when they are receiving contraceptive counselling. 


\section{Methods}

Contraceptive counselling in Sweden is free of charge. Physicians as well as midwives can provide this counselling, but commonly midwives are the counsellors. During a visit at a family planning clinic the midwife will provide contraceptive counselling, ask questions about medical history, measure blood pressure, weight, and height (the latter for defining the woman's BMI). The midwife may even ask the woman about her life style habits, for example her use of tobacco and alcohol. The midwife gives positive and negative feedback to the woman and will pay attention to the good as well as harmful parts of what she is told. She also offers the woman the chance to discuss these behaviours. If needed, the midwife carries out a gynaecological examination. A visit for contraceptive counselling is 30 minutes. The midwife is licensed to prescribe all available hormonal contraceptive methods. Swedish women taking oral hormonal contraceptives as well as those who have a patch or vaginal ring are recommended to visit a family planning clinic every second to third year for medical check-up.

Swedish-speaking women $(\mathrm{n}=802)$ who visited a midwife in a family planning clinic in Linköping during a 6-month period in 2010 were asked to complete a study-specific anonymous questionnaire after their visit. The questionnaire comprised of 18 questions covering socio-demographic factors, assessment of the women's general health status and alcohol habits. Further, the women were asked to estimate the importance of discussing alcohol habits at a contraceptive counselling. The study participants were also asked on the impression of the discussion with the midwife concerning alcohol- and tobacco habits and the weight, whether the discussion was intrusive, embarrassing or a good thing. They were also asked if any other medical health care giver other than a midwife had asked them about their alcohol habits during the preceding year. Finally, they were asked to give their opinion about important factors in general that might decrease people's consumption of alcohol. The 
completed form was dropped by the women themselves in a box at the reception of the clinic. A total of 535 women $(67 \%)$ answered the questionnaire.

Concerning the women's alcohol habits the Alcohol Use Disorders Identifications Test Consumption (AUDIT-C) questionnaire was used [22]. The questions concern frequency of drinking, typical quantity of alcohol consumed and frequency of binge drinking (i.e., consuming a larger quantity at one occasion) during the preceding year. Each of the questions has a set of five responses to choose between, and each response has a score ranging from 0 to 4 points to yield a summary score ranging from 0 to 12 . The threshold for alcohol misuse has been discussed. Bush et al. [22] and Bradley et al. [23] suggest in their studies including a population of US women $\geq 3$ as a cut-off point, whereas a study by Rumpf et al. [24] in a North European population recommend a cut-off point of $\geq 5$. In a Swedish study among pregnant women the cut-off point of $\geq 6$ was used for expanded information and advice [25]. In this study the same cut-off level is used. The AUDIT form was filled in by the women during the visit. No extra time was added to the normal given time for contraceptive counselling.

In a sub-analysis we evaluated data depending on the AUDIT points. Women who got less than 6 AUDIT-points constituted a low risk group (LRG) and women who got 6 or more AUDIT-C points constituted a high risk group (HRG).

The study was conducted following the ethical principles of the Helsinki Declaration

\section{$\underline{\text { Statistics }}$}

All analyses were performed using the IBM SPSS programme, version 19.0(IBM Corp., Armonk, NY, USA). Statistical significance was defined as (two-sided) $p \leq 0.05$. Data are reported as numbers and percentages. Group differences were estimated by using the Chisquare test on categorical variables. Furthermore, to make a more comprehensive assessment 
of group differences between the LRG and HRG, binary logistic regressions were performed with the participators' experience and attitudes towards discussing alcohol- and tobacco habits and weight as dependent variables. These two variables were dichotomized into agree (containing three positive answering alternatives) and disagree. The grouping variables have been adjusted for age, parity, marital status, tobacco use, education level, assessment of general health and group. 


\section{Results}

Background characteristics and lifestyle habits among the women $(n=535)$ who participated in the study are displayed in Tables 1 and 2 . We also investigated the background characteristics in the LRG and HRG (Table 3).

A majority of the women $(72.9 \%)$ stated that no caregiver other than the midwife had discussed drinking habits with them during the preceding year, whereas $7.1 \%$ said that they had talked about this at a visit in primary care. Fewer than $4 \%$ of the women had discussed this habit at the adolescent-, student- and/or occupational health service. Most of the women $(85.5 \%)$ also stated that a discussion concerning alcohol habits is important at a contraceptive counselling session (Table 2). In a sub-analysis we investigated whether this opinion differed between women in the LRG and HRG, but no significant difference was found $(\mathrm{p}=0.821)$.

The study participants' experience and attitudes towards discussing alcohol and tobacco habits and the weight with the midwife are shown in Table 4. A majority of the women thought that the discussion about alcohol and tobacco habits and the weight was not intrusive or embarrassing and that it was a good thing that the midwife brought up the topic for discussion. In a sub-analysis we investigated the differences of these impressions, between the LRG and HRG. There was a significantly higher percentage of women in the HRG who thought that the discussion about alcohol habits was intrusive $(10.9 \%)$ and embarrassing (46.7\%), compared with women in the $\operatorname{LRG}(5.3 \%, 6.9 \%$ respectively $)(p=0.008, p<0.001$ respectively). There was also a higher percentage of women in the HRG who thought that the discussion about tobacco use (35.3\%) and weight (42.1\%) was embarrassing, compared with women in the LRG $(7.9 \%, 19.4 \%$ respectively $)(\mathrm{p}<0.001, \mathrm{p}=0.011$ respectively $)$. After adjusting these two dependent variables for socio-demographic factors there was still a 
difference between the two groups concerning whether the discussion about the alcohol and tobacco habits and weight was embarrassing (alcohol; odds ratio (OR) 13.86, confidence interval (CI) 6.77-28.36, $\mathrm{p}<0.001$, tobacco use; OR 2.86, CI 1.14-7.17, $\mathrm{p}=0.026$, weight; OR 2.64 CI 1.27-5.48, $\mathrm{p}=0.009)$. There was no difference between the groups concerning the opinion that it was good that the midwife brought up the topic for discussion $(\mathrm{p}=0.277)$.

The women were further asked to assess which factors might influence people in general to decrease or stop drinking. A majority of the women considered that poor health $(91.6 \%)$, partner (78.1\%), friends (76.7 \%) and health professionals $(68.8 \%)$ had an important influence on decision-making. Media had an unimportant influence according to $68.0 \%$ of the study population. In the following sub analysis we found that significantly fewer women in the HRG (54.4\%) said that health professionals had an important influence on the decision to decrease or stop drinking, compared with the women in the LRG $(74.4 \%)(\mathrm{p}=0.028)$. 


\section{Discussion}

In this large descriptive study a majority of the women stated that a discussion taking place during contraceptive counselling concerning alcohol habits and their weight was important. Only half of the women found a discussion about tobacco use important. A significantly higher percentage of women in the HRG thought that the discussion about their weight, alcohol and tobacco use was intrusive and embarrassing compared with women in the LRG. Most women had not discussed drinking habits during the preceding year with any health caregiver other than the midwife. The midwives in the Swedish antenatal and contraceptive units are familiar with discussing life style factors when facing pregnant women. The climate during these talks is critical for the result. The more the talk is characterized by empathy and respect for the situation of the women the more relaxed the conversation will be. The concept of motivational interviewing is useful when the aim of the talk is to make conscious of the problem and to increase the motivation for changing habits [26]. Most of the Swedish midwives are familiar with this concept and use it when they meet pregnant women. The concept might also be useful when discussing life style habits in contraceptive counselling situations. As there was a greater percentage of women in the HRG than among the women in the LRG who thought that the discussion about the weight, tobacco and alcohol habits was intrusive and embarrassing, it is challenging for the midwife to design a discussion where all women can feel comfortable and in line with the spirit of motivational interviewing, i.e. an approach characteristic of collaboration about a change, but also with respect for the women's decision not to make a change [26]. A majority of the women in the HRG stated that they were planning for childbirth in the future. Based on this fact, the midwife has an important task to provide information about the importance of abstaining from alcohol when planning for pregnancy. 
The area of lifestyle habits does not always have an obvious place in the discussion with caregivers. In a study by Johansson et al. [15] the majority of the patients reported that they could not recall having received any lifestyle advice at their most recent visit at the primary care centre, whereas in the study by Ahacic et al. [17] 19-30\% of the women reported that they had discussed life style habits at health care visits during the preceding year. These results differ from what general practitioners (GPs) and nurses in primary health care report [16]. The GPs stated that they frequently (more than $80 \%$ ) discussed smoking and exercise habits with their patients, whereas the nurses discussed these areas with 70-80\% of their patients. Alcohol habits were considered to a much lower degree, $50 \%$ and $28 \%$ of GPs and nurses respectively [16]. On the other hand, only a total of $19 \%$ of the female participants in the study by Ahacic et al. [17] reported that they had been questioned about alcohol use and only $1 \%$ of the women stated that they had received any advice or help, whereas $5 \%$ of all participants in the study by Johansson et al [15] reported being given advice on the alcohol issue. In this last mentioned study there was a gender difference. Male patients received advice more than twice as often as female patients [15]. In the present study $7 \%$ reported that they had discussed alcohol habits at visits in primary health care during the preceding year, but most of the women stated that no caregiver other than the midwife had asked questions about alcohol habits during the past year. An explanation could be that women in this sample were a quite healthy group and therefore only had visited primary care on a few occasions. Another explanation could be that it is still taboo to discuss alcohol habits among women.

A majority of the participants in this study stated the importance of discussing alcohol issues at a contraceptive counselling visit and declared that it was good that the midwife brought up the topic for discussion. The care seeker's view really differs from the care givers. Around 15-17\% of GPs and nurses reported that the reason for not addressing alcohol issue was the 
potentially negative patient response [16]. In the study by Johansson et al. [15] around $35 \%$ of the female patients expected being given advice about alcohol use but did not receive it at the visit with the GP. The patients who received advice were more satisfied with the visit than those who did not receive advice.

The HRG shows differences in comparison with the sample of women who engage in highrisk drinking in "Health on Equal Terms? - The National Survey of Public Health" (HET) study [27]. The Public Health Agency of Sweden investigates every year the health situation in the population. A sample of 20000 men and women in age 16-84 years, are asked to complete the questionnaire HET encompassing questions about living habits (e.g. alcohol and tobacco use, physical activity, eating habits, overweight and obesity). In the present study the percentage of younger women ( $<30$ year) engaging in high risk drinking was greater than among women in the same age-class ( $<30$ year) in HET, $85 \%$ versus $24 \%$. The percentage of students $(40 \%)$ in the present study was also higher than the percentage of students in the HET (10\%). Alcohol habits among students have been studied earlier [28-31]. Dantzer et al. [28] investigated heavy drinking habits (four drinks or more on at least one occasion over the past 2 weeks) among 10000 female students aged 17-30 years in 21 developed and developing countries and found wide variations in the prevalence of drinking at this level. A total of $3 \%$ of female students in Germany, Italy and South Africa reported heavy drinking, whereas $57 \%$ of Irish female students reported the same. A study by Andersson et al. [29] aiming to analyse drinking habits among 1300 university students showed that more than 50 $\%$ of female students younger than 26 years old reported heavy episodic drinking, defined as four or five drinks or more at one occasion. The corresponding rate for female students in age-class 26-30 was $39 \%$. Among male as well as female students the proportion of risky drinkers were around $56 \%$ [30]. Risky alcohol habits, defined as AUDIT-C $\geq 5$ points have 
been investigated in a sample of 300 female medical students [31]. Twenty-four per cent of these students were risky drinkers during their first study year.

A total of 103 women were tobacco users but only $86 \%$ of them reported that they had discussed tobacco habits at the visit. It is possible that this part of the counselling which consisted of two questions only had passed faster than the parts concerning alcohol habits and weight/BMI. The woman was asked to complete the AUDIT form and that led obviously to a more extensive follow-up discussion. The circumstances might have been the same when it comes to weight. A reflection and discussion followed obviously after measuring the weight and calculating the woman's actual BMI. On the other hand, the midwife who also takes care of pregnant women is familiar with tobacco issues. It is thought possible that tobacco use during pregnancy emphasized deeper discussions than among non-pregnant patients.

This study has weaknesses as well as strengths. Unfortunately, information on the woman's actual BMI at the visit was not available which makes comparisons of attitudes towards discussing weight impossible over the BMI strata. The selected cut-off point is based on previous study result [25]. A lower cut-off level would increase the number of women belonging to the HRG and possibly the relationship between the two groups. However, this study is, to our knowledge, the first one investigating opinions about discussing life style factors in contraceptive counselling and our results indicate that a majority of the women found a discussion concerning alcohol habits and weight as important at the contraceptive counselling. Our results also indicate that fewer women in the HRG assessed that health professionals had an important influence on making a decision to decrease or stop drinking, compared with the women in the LRG. Therefore there is a challenge for midwives who face women in contraceptive counselling to develop the information in an appropriate manner. 


\section{Declaration of Conflicting Interests}

The authors declare that there is no conflict of interest 


\section{References}

1. Swedish National Institute for Public Health. Övervikt och fetma - tidsserier och regionala resultat 2013. . Available at http://www.folkhalsomyndigheten.se/amnesomraden/statistikoch-undersokningar/enkater-och-undersokningar/nationellafolkhalsoenkaten/levnadsvanor/overvikt-och-fetma/ Retrieved February 2014.

2. Swedish National Institute for Public Health. Alkoholvanor - tidsserier och regionala resultat 2013. . Available at: http://www.folkhalsomyndigheten.se/amnesomraden/statistik-ochundersokningar/enkater-och-undersokningar/nationellafolkhalsoenkaten/levnadsvanor/alkoholvanor/ Retrieved February 2014.

3. Andréasson SAPLHSf. Alkohol och hälsa : en kunskapsöversikt om alkoholens positiva och negativa effekter på vår hälsa. Stockholm: Statens folkhälsoinstitut; 2005.

4. Swedish National Institute for Public Health. Tobaksvanor tidsserier och regionala resultat 2013. Available at: http://www.folkhalsomyndigheten.se/amnesomraden/statistik-ochundersokningar/enkater-och-undersokningar/nationellafolkhalsoenkaten/levnadsvanor/tobaksvanor/ Retrieved February 2014.

5. Whitlock $G$, Lewington $S$, Sherliker $P$, et al. Body-mass index and cause-specific mortality in 900000 adults: collaborative analyses of 57 prospective studies. Lancet. 2009 Mar 28;373[9669]:1083-96.

6. Rehm J, Mathers C, Popova S, et al. Global burden of disease and injury and economic cost attributable to alcohol use and alcohol-use disorders. Lancet. 2009;373[9682]:2223-33.

7. World Health Organization. Management of Substance Abuse T. Global status report on alcohol and health. Geneva, Switzerland: World Health Organization; 2011.

8. Freedman ND, Leitzmann MF, Hollenbeck AR, et al. Cigarette smoking and subsequent risk of lung cancer in men and women: analysis of a prospective cohort study. The lancet oncology. 2008 Jul;9[7]:649-56.

9. Cedergren M. Maternal morbid obesity and the risk of adverse pregnancy outcome. Obstet Gynecol. 2004;103:219-24.

10. Nohr EA, Vaeth M, Baker JL, et al. Pregnancy outcomes related to gestational weight gain in women defined by their body mass index, parity, height, and smoking status. Am J Clin Nutr. 2009 Nov;90[5]:1288-94.

11. Astley SJ. Fetal alcohol syndrome prevention in Washington State: evidence of success. Paediatr Perinat Epidemiol. 2004 Sep;18[5]:344-51.

12. Goodlett CR, Horn KH, Zhou FC. Alcohol teratogenesis: mechanisms of damage and strategies for intervention. Experimental biology and medicine. 2005 Jun;230[6]:394-406.

13. Tsukamoto $H$, Fukuoka $H$, Koyasu $M$, et al. Risk factors for small for gestational age. Pediatrics international : official journal of the Japan Pediatric Society. 2007 Dec;49[6]:98590.

14. Gunnerbeck A, Wikstrom AK, Bonamy AK, et al. Relationship of maternal snuff use and cigarette smoking with neonatal apnea. Pediatrics. 2011 Sep;128[3]:503-9.

15. Johansson K, Bendtsen P, Akerlind I. Advice to patients in Swedish primary care regarding alcohol and other lifestyle habits: how patients report the actions of GPs in relation to their own expectations and satisfaction with the consultation. Eur J Public Health. 2005 Dec;15[6]:615-20.

16. Holmqvist $\mathrm{M}$, Bendtsen $\mathrm{P}$, Spak $\mathrm{F}$, et al. Asking patients about their drinking. A national survey among primary health care physicians and nurses in Sweden. Addictive behaviors. 2008 Feb;33[2]:301-14.

17. Ahacic K, Allebeck $P$, Thakker KD. Being questioned and receiving advice about alcohol and smoking in health care: associations with patients' characteristics, health behavior, and reported stage of change. Substance abuse treatment, prevention, and policy. 2010;5:30. 
18. Goransson M, Magnusson A, Bergman H, et al. Fetus at risk: prevalence of alcohol consumption during pregnancy estimated with a simple screening method in Swedish antenatal clinics. Addiction. 2003 Nov;98[11]:1513-20.

19. Harrison PA, Sidebottom AC. Alcohol and drug use before and during pregnancy: an examination of use patterns and predictors of cessation. Matern Child Health J. 2009 May;13[3]:386-94.

20. Nilsen P, Skagerstrom J, Rahmqvist M, et al. Alcohol prevention in Swedish antenatal care: effectiveness and perceptions of the Risk Drinking project counseling model. Acta Obstet Gynecol Scand. 2012 Jun;91[6]:736-43.

21. Prevention CfDCa. Alcohol Use and Binge Drinking Among Women of Childbearing Age United States, 2006-2010. Avaible at: http://www.cdc.gov/mmwr/preview/mmwrhtml/mm6128a4.htm?s cid=mm6128a4 w Accessed July 20, 2012.

22. Bush K, Kivlahan DR, McDonell MB, et al. The AUDIT alcohol consumption questions (AUDITC): an effective brief screening test for problem drinking. Ambulatory Care Quality Improvement Project (ACQUIP). Alcohol Use Disorders Identification Test. Arch Intern Med. 1998 Sep 14;158[16]:1789-95.

23. Bradley KA, DeBenedetti AF, Volk RJ, et al. AUDIT-C as a brief screen for alcohol misuse in primary care. Alcoholism, clinical and experimental research. 2007 Jul;31[7]:1208-17.

24. Rumpf HJ, Hapke U, Meyer C, John U. Screening for alcohol use disorders and at-risk drinking in the general population: psychometric performance of three questionnaires. Alcohol and alcoholism. 2002 May-Jun;37[3]:261-8.

25. Nilsen $\mathrm{P}$, Holmqvist $\mathrm{M}$, Bendtsen $\mathrm{P}$, et al. Is questionnaire-based alcohol counseling more effective for pregnant women than standard maternity care? J Womens Health (Larchmt). 2010 Jan;19[1]:161-7.

26. Miller WR, Rollnick S. Motivational interviewing : preparing people for change. 2 ed. New York: Guilford Press; 2002.

27. Swedish National Institute for Public Health. Health on Equal Terms? - The National Survey of Public Health. Available at http://www.folkhalsomyndigheten.se/amnesomraden/statistik-ochundersokningar/enkater-och-undersokningar/nationella-folkhalsoenkaten/ Retrieved February 2014.

28. Dantzer C, Wardle J, Fuller R, et al. International study of heavy drinking: attitudes and sociodemographic factors in university students. Journal of American college health : J of ACH. 2006 Sep-Oct;55[2]:83-9.

29. Andersson A, Wirehn AB, Olvander $C$, et al. Alcohol use among university students in Sweden measured by an electronic screening instrument. BMC Public Health. 2009;9:229.

30. Bendtsen P, McCambridge J, Bendtsen M, et al. Effectiveness of a proactive mail-based alcohol Internet intervention for university students: dismantling the assessment and feedback components in a randomized controlled trial. Journal of medical Internet research. 2012;14[5]:e142.

31. Ketoja J, Svidkovski AS, Heinala P, Seppa K. Risky drinking and its detection among medical students. Addictive behaviors. 2013 May;38[5]:2115-8. 
Table 1. Background characteristics of the study population $(n=535)$

\begin{tabular}{|c|c|c|}
\hline & $\mathbf{N}$ & $\%$ \\
\hline \multicolumn{3}{|l|}{ Age; years } \\
\hline$\leq 19$ & 13 & 2.4 \\
\hline$\overline{2} 0-24$ & 146 & 27.3 \\
\hline $25-29$ & 163 & 30.5 \\
\hline $30-34$ & 61 & 11.4 \\
\hline $35-39$ & 69 & 12.9 \\
\hline$\geq 40$ & 81 & 15.1 \\
\hline$\overline{\text { Did not reply }}$ & 2 & 0.4 \\
\hline \multicolumn{3}{|l|}{ Parity } \\
\hline No previous children & 327 & 61.1 \\
\hline$\geq 1$ previous children & 205 & 38.3 \\
\hline Did not reply & 3 & 0.6 \\
\hline \multicolumn{3}{|c|}{ Planning for childbirth in the future ${ }^{a}$} \\
\hline Yes & 327 & 72.3 \\
\hline No & 119 & 26.3 \\
\hline Did not reply & 6 & 1.3 \\
\hline \multicolumn{3}{|l|}{ Marital status } \\
\hline Married/cohabiting & 336 & 62.8 \\
\hline Other family situation & 196 & 36.7 \\
\hline Did not reply & 3 & 0.6 \\
\hline \multicolumn{3}{|l|}{ Education level; year } \\
\hline$\leq 9$ & 16 & 3.0 \\
\hline$\overline{10}-12$ & 193 & 36.1 \\
\hline$\geq 13$ & 320 & 59.8 \\
\hline$\overline{\text { Did not reply }}$ & 6 & 1.1 \\
\hline \multicolumn{3}{|l|}{ Occupation status } \\
\hline Gainfully employed & 362 & 67.7 \\
\hline Unemployed & 25 & 4.7 \\
\hline Student & 124 & 23.2 \\
\hline Leave of absence & 15 & 2.8 \\
\hline Sick-leave & 7 & 1.3 \\
\hline Did not reply & 2 & 0.4 \\
\hline
\end{tabular}

${ }^{\text {a }}$ Among women $<40$ years 
Table 2. Lifestyle habit inventory of the study population $(n=535)$

\begin{tabular}{|c|c|c|}
\hline & $\mathbf{N}$ & $\%$ \\
\hline \multicolumn{3}{|c|}{ Assessment of general health } \\
\hline Excellent & 86 & 16.1 \\
\hline Very good & 272 & 50.8 \\
\hline Good & 148 & 27.7 \\
\hline Fairly good & 27 & 5.0 \\
\hline $\mathrm{Bad}$ & 0 & 0.0 \\
\hline Did not reply & 2 & 0.4 \\
\hline \multicolumn{3}{|l|}{ Tobacco users } \\
\hline No & 429 & 80.2 \\
\hline Yes & 103 & 19.3 \\
\hline Did not reply & 3 & 0.6 \\
\hline \multicolumn{3}{|c|}{ Discussed tobacco habits at the visit ${ }^{a}$} \\
\hline No & 12 & 11.7 \\
\hline Yes & 89 & 86.4 \\
\hline Did not reply & 2 & 1.9 \\
\hline \multicolumn{3}{|c|}{ Discussed the weight/BMI ${ }^{\mathrm{b}}$ at the visit } \\
\hline No & 72 & 13.5 \\
\hline Yes & 456 & 85.2 \\
\hline Did not reply & 7 & 1.3 \\
\hline \multicolumn{3}{|c|}{$\begin{array}{l}\text { The importance of discussing alcohol } \\
\text { habits at a contraceptive counselling }\end{array}$} \\
\hline Very important & 209 & 39.1 \\
\hline Quite important & 248 & 46.4 \\
\hline Not so important & 66 & 12.3 \\
\hline Not at all important & 6 & 1.1 \\
\hline Did not reply & 6 & 1.1 \\
\hline \multicolumn{3}{|l|}{ AUDIT $^{c}$ points } \\
\hline$<6$ points & 467 & 87.3 \\
\hline$\geq 6$ points & 47 & 8.8 \\
\hline Did not reply & 21 & 3.9 \\
\hline \multicolumn{3}{|c|}{ Frequency of drinking over the past year } \\
\hline Abstainer & 21 & 3.9 \\
\hline Once a month or less & 165 & 30.8 \\
\hline 2-4 times per month & 287 & 53.6 \\
\hline 2-3 times per week & 50 & 9.3 \\
\hline 4 times per week or more & 6 & 1.1 \\
\hline Did not reply & 6 & 1.1 \\
\hline \multicolumn{3}{|c|}{ Typical quantity of drinking among users } \\
\hline $1-2$ standard glasses $\dagger$ & 237 & 44.3 \\
\hline
\end{tabular}


3-4 standard glasses

5-6 standard glasses

7-9 standard glasses

$12 \quad 2.2$

10 or more standard glasses

$2 \quad 0.4$

Did not reply

$21 \quad 3.9$

Frequency of heavy episodic drinking (6 glasses or more per occasion)

Never drink heavy episodic

Less often than once a month

$275 \quad 51.4$

Every month

$49 \quad 9.2$

Every week

$10 \quad 1.9$

Daily or almost daily

$0 \quad 0$

Did not reply

$14 \quad 2.6$

\footnotetext{
a Among tobacco users.

${ }^{\mathrm{b}}$ BMI = Body Mass Index.

${ }^{c}$ Alcohol Use Disorder Identification Test.

$\dagger 1$ standard glass $=12 \mathrm{~g}$ of pure alcohol.
} 
Table 3. Background characteristics among women in the low- and high risk group concerning their points in the Alcohol Use Disorders Identifications Test; < or $\geq 6$ points

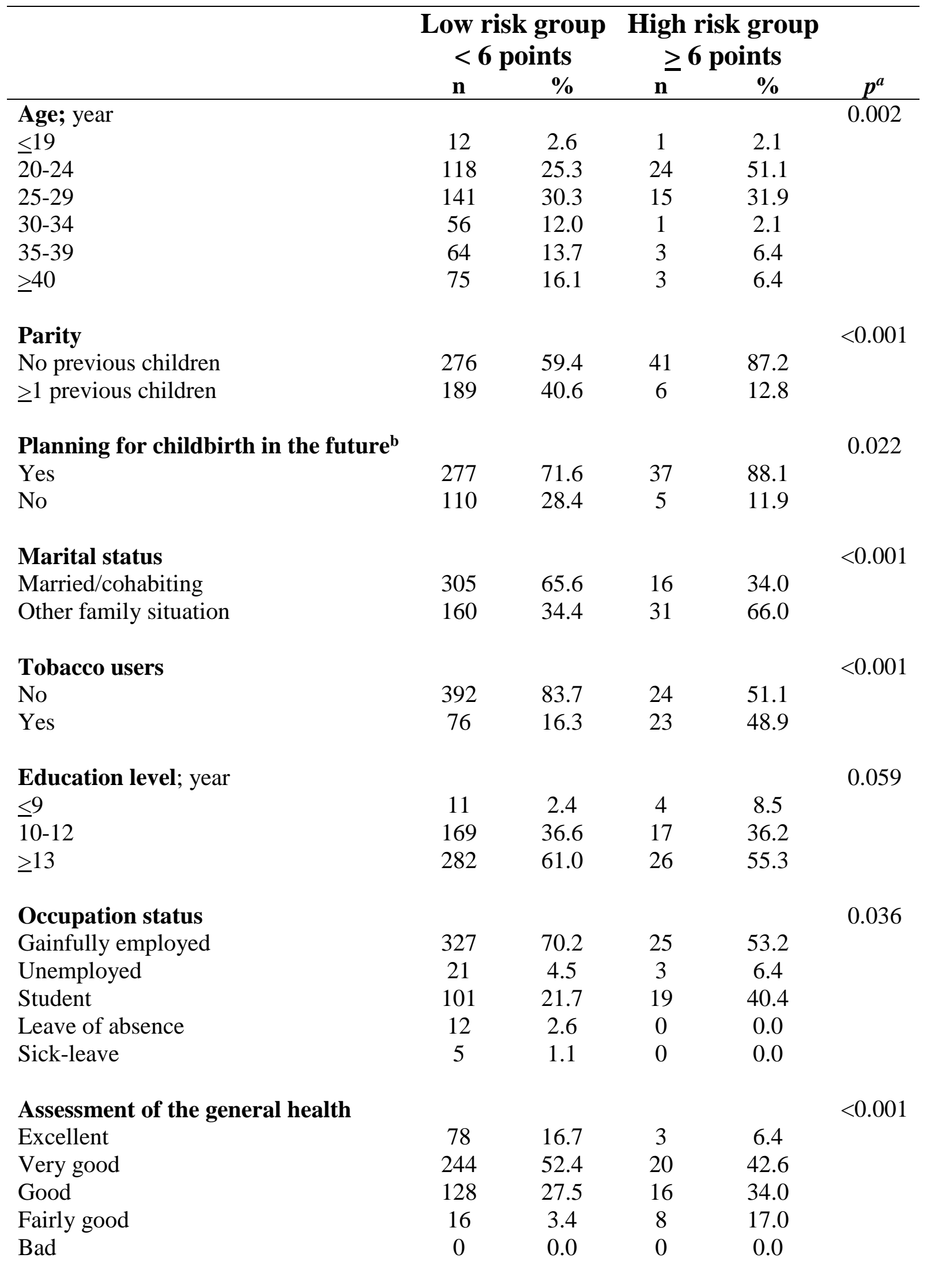

\footnotetext{
${ }^{a}$ Comparison between LRG $(<6 \mathrm{p})$ and HRG $(\geq 6 \mathrm{p})$ was made using chi square test
} 
${ }^{\mathrm{b}}$ Among women $<40$ years 
Table 4. The study participators' impression of the discussion with the midwife concerning alcohol and tobacco habits and the weight.

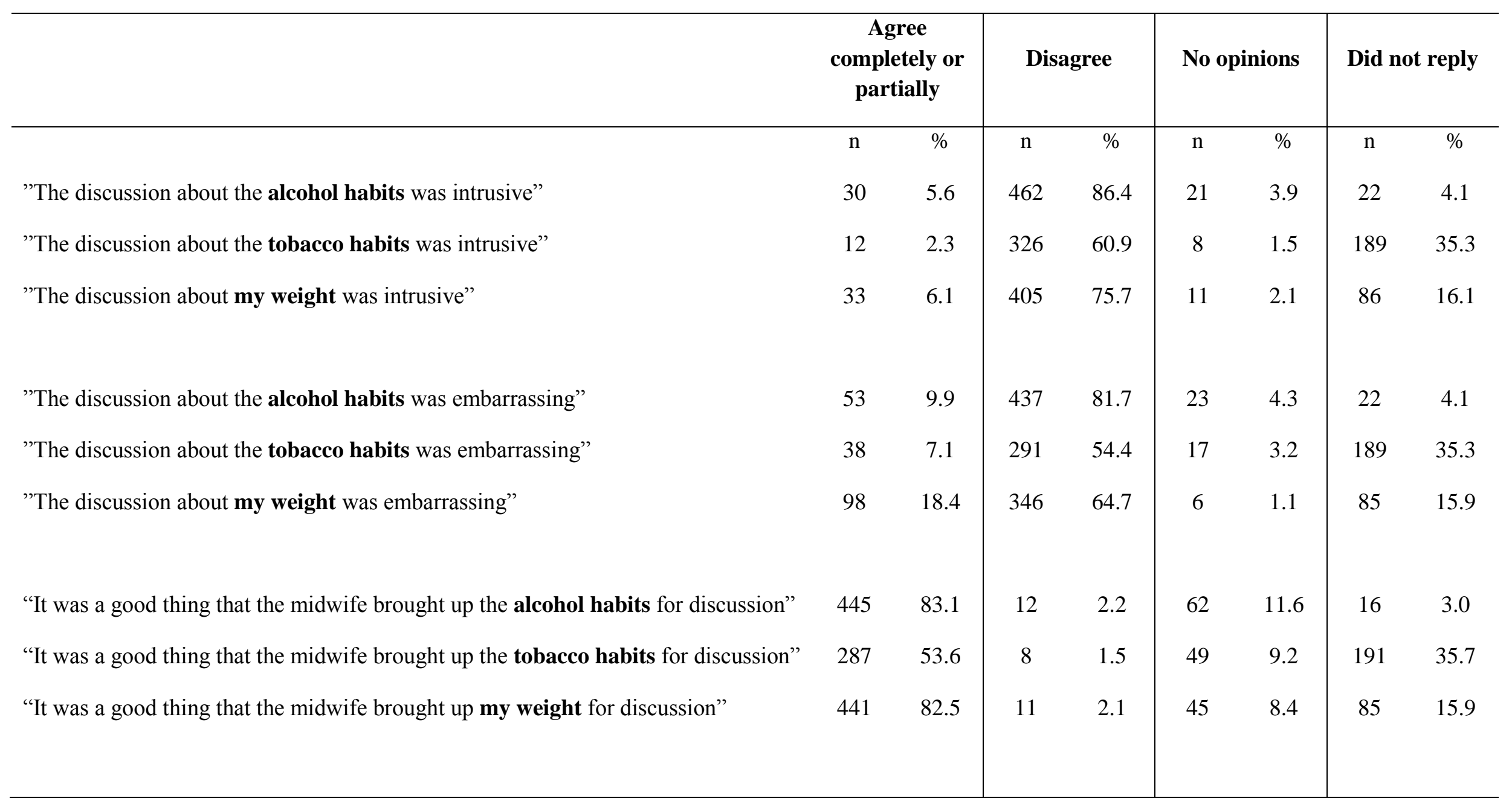

